\title{
A History of the Johns Hopkins Center for Alternatives to Animal Testing (CAAT): The First 28 Years (1981-2009)
}

\author{
Alan M. Goldberg
}

Key words: cosmetics, environmental chemicals, in vitro methods, pharmaceuticals.

\section{A History of Center for Alternatives to Animal Testing}

$\mathbf{I}$ N 1980, D.A. Henderson, the dean of the Johns Hopkins School of Hygiene and Public Health (now the JHU Bloomberg School of Public Health, BSPH), was approached by Robert (Bob) Worsfold, president of Estee Lauder International, director of the Cosmetic Toiletries and Fragrance Association (CTFA, now CPCP), and a member of the school's Health Advisory Council. Bob asked D.A. if the school could help the cosmetic industry address the issue of animal testing and begin to develop nonanimal methods. Animal activists, he explained, were giving the industry a black eye and they were interested in developing different approaches for testing the toxicity and safety of their products. The industry had pledged the funding and was prepared to spend 1 million dollars over 3 years. In their conversation, D.A. recommended that the program be established at a university, as 3 years was a short time and developing a new entity would be more time-consuming and possibly less productive than incorporating the program into a university. D.A. was aware that I had published an article on in vitro toxicology using tissue culture methods ${ }^{1-3}$ and asked Gareth Green, chairman of the Department of Environmental Health Sciences (EHS), if this was something with which we should get involved. At the time, I was the director of the division of toxicology in EHS.

Gareth called me and asked, "If you had a million dollars how would you eliminate animal testing in the cosmetic industry?" He suggested that we discuss how to address Bob's ideas for creating a less hostile environment between animal rights groups and CTFA and its members. The three of us-D.A., Gareth, and myself-scheduled a meeting to discuss the issue. As I recollect, the issues we labored over were as follows: How would the scientists at the university feel about such a center? What should we name it? How would the grant ( $\$ 1$ million from the CTFA) impact on the school?

\section{University Acceptance}

The university would accept the grant only if it was driven by a scientific agenda. I was warned that I should expect personal rejection by some colleagues, but I was unprepared for how extensive the rejection would be. It came on two fronts - the perception of my work on what were understood as "animal rights" issues and the rejection of applied research. One of my postdoctoral fellows drew a picture of an airplane with engines pointing in different directions and several different-sized wings. In short, he explained that what we were planning had a resemblance to an airplane but would not fly. It was labeled, "If industry is interested we will build it."

Rejection-or at least openly stated rejection-is no longer an issue. The search for alternatives and in vitro methods for understanding mechanisms of toxicity is inarguably the main focus of toxicological research today. In the words of Thomas Kuhn, ${ }^{4}$ we have undergone a scientific revolution.

\section{What's in a Name?}

Although we didn't decide on a name by the end of the meeting, we were in agreement that the word "alternative" was to be part of it. Discussions continued for several weeks, even after the grant was submitted. The word "complimentary" was rejected as we believed, and we have been proven correct that in vitro approaches would eventually replace animal testing. "Alternative," however, came from the animal welfare world and was defined by the so-called 3R's: replacement (replacing in vivo with nonanimal methods), refinement (decreasing pain and discomfort for animals in a study - from housing to experimental procedures to euthanasia at the end of the study), and reduction (reducing the number of animals needed to the minimum). Reduction, in fact, is about equivalent to improving experimental design. The name we identified, relatively early on-“"The Johns Hopkins Center for Alternatives to Animal Testing", (CAAT)—became the brand.

Bloomberg School of Public Health and Global Food Ethics Project, Johns Hopkins University, Baltimore, Maryland.

(c) Alan M. Goldberg 2015; Published by Mary Ann Liebert, Inc. This Open Access article is distributed under the terms of the Creative Commons Attribution Noncommercial License (http://creativecommons.org/licenses/by-nc/4.0/) which permits any noncommercial use, distribution, and reproduction in any medium, provided the original author(s) and the source are credited. 


\section{Size of the Grant}

At that time, ours was the single largest corporate-funded project at the university. The average NIH grant was just under $\$ 40 \mathrm{~K} /$ year, and this was almost 10 times that amount. Concerns were significant-in particular, fears that the amount of money for one laboratory would spur rapid growth of a single project, with the possibility that three years down the road there could be a large number of unfunded projects. The grants program was developed as part of CAAT's mission to address precisely this concern by providing small grants to both Hopkins researchers and researchers around the world.

\section{Impact on the School}

Over 30 years later, CAAT's establishment is regarded as a significant event for the Bloomberg School of Public Health. It opened up the school to industrial sources of support by creating the necessary contacts in the business community.

Shortly before the center was established, during the presidency of Steven Muller, the university initiated a fundraising campaign. The School of Public Health, lacking significant contacts within industry, was rarely mentioned in letters to potential sponsors. After CAAT's establishment, the school was included in almost every letter sent during the next campaign, as CTFA represented over 400 companies. At that time, the individual companies contributing to the fund were not identified, only the CTFA.

\section{The Proposal}

Gareth, D.A., and I spent an hour or two talking about how to develop the proposal. Gareth ran the Environmental Protection Agency (EPA) grants program and asked me to assist him. We knew something about funding grants and realized that small grants, about $\$ 20,000$, could be spread over many laboratories at Hopkins and other institutions to develop the foundation for in vitro toxicology. This solved many issues-notably, that we would need to create a giant laboratory at Hopkins. The proposed grants would enable the best scientists to develop in vitro methodologies that would become the basis for new test development.

The vision became clear. CAAT would focus on supporting the development of in vitro cell-based assays to replace animal tests for regulatory purposes.

After the discussion, I was charged with drafting the proposal. That night, after dinner, my wife, Helene, asked what I was planning for the evening. I told her that I was going to write a grant and that she could read it before bedtime. She laughed-a complete grant in the next few hours?

I got my legal-sized yellow pad and a pencil, and started writing. I completed a first draft that evening. It contained the following concepts:

1. The grants program (not more than half of the research funds would go to Hopkins)

2. A Hopkins laboratory

3. A director's discretionary research fund (to assist projects that could be funded for $\$ 3000$ or less)

4. Funds to develop and pay for an advisory board and an administrative core that provided salaries for me, a secretary, office supplies, and a computer

This was 1981. We also promised to provide quarterly progress reports to CTFA.

\section{The CTFA Grant Was Funded}

September 21st, 1981

We held a press conference at the school on Friday, September 21, 1981, to announce the center and its anticipated program. We had very good press coverage and the center was off and running. We had been advised to have security present because of the animal activist community. I do not think anyone from that community came, however, and there were no protests. Why would there be? We were doing the work they wanted. I was soon to learn how naïve I was.

On Monday, September 24th, two significant events occurred. The first was that Henry Spira, the man who browbeat the industry into reconsidering their practices, showed up in my office. The director of the CTFA communications program had already met with me and suggested (actually told me) how to deal with Henry once he contacted me-to ignore him. Advice I have since learned was not good in this situation and generally is not good advice in most instances. Thus, when Henry showed up to discuss plans for the center, I listened, did not comment or engage him in a discussion, provided no information, and after he finished, I suggested he read the material we would publish-the science-and told him he could use that as it would be in the public domain. Then I ushered him from my office (and I cringe as I write this).

That same day, my wife was working at the ICCU at Hopkins. When she went in for her shift, the head of the unit looked at her, looked at her feet, and said, "Still wearing leather shoes." She had no idea what he meant by that. I explained to her that evening that we were now considered "animal activists" who would never wear leather shoes"little old ladies in tennis shoes." To some, it might have seemed that I had crossed the line from scientist and colleague to animal activist. For those that knew me, however, I was (and still am) a scientist with an understanding and appreciation of humane science. As stated eloquently by Bill Russell and Rex Burch, authors of The Principles of Humane Experimental Technique, the best science is the most humane science.

\section{Setting up the Center}

In addition to D.A., Gareth, and me, we asked Henry Wagner and Franklin (Frank) Loew to assist in organizing the project. The major initial activities were getting the advisory board together, organizing its first meeting, and planning to solicit grants. External communication was not on the table. Frank suggested that we approach Andrew Rowan of the Humane Society of the United States (HSUS) to become a member of the board as a representative of the animal protection community and to be my mentor on animal welfare issues. We realized that we needed academics with specific areas of research (such as eye and skin), representatives from the government (FDA, National Institute of Environmental Health Sciences [NIEHS], and EPA), and industry sponsors. D.A. and Gareth identified and recruited the government representatives. For the FDA, the then commissioner was approached and he appointed Gerald Guest. John (Jack) Moore, an associate director of the EPA, accepted the invitation and Paul Kotin, the first director of the NIEHS, also accepted the invitation. The academics 
included Lowell Goldsmith, chairman of dermatology at Rochester, and James ( Jim) McCulley, chairman of ophthalmology at Dallas Southwestern Medical School. From industry, we invited Norman Estrin, a representative of the CTFA, and Leon Golberg of the Chemical Industries Institute of Toxicology (now the Hamner Institutes for Health Science).

Although most of these people knew of each other, they were all new to me. The first board meeting took place in Baltimore in February 1982, during a miserable snow storm. Nonetheless, everyone made it. The last to arrive was Jim McCulley. His plane had been diverted and he had to come by bus from Philadelphia. When he walked into the room, he was looking over the crowd, and I approached him, not knowing who he was. He asked, "Is this the Hopkins meeting?" As I type this, I cannot believe how vivid the memories are and what great fortune I had to have the initial advisors put together such a talented, knowledgeable, and selfless group of individuals. Most of us became true friends over the years. But most importantly, the board seemed to care only about CAAT, its mission, and how to achieve our stated goals. What follows does not fit a history and is very personal: I feel blessed to have known and worked with these people and to have directed CAAT for 28 years.

The first board meeting set the tone for the next 28 years and a little beyond. At the first board meeting, we began a practice that is still followed today: After we went around the table and introduced ourselves, we then went around the table again and each person expressed why they were willing to donate their time (we paid hotel and travel expenses). Each meeting ends with a final hour-plus go around the table, providing an opportunity to repeat something that was said, share an understanding or concern, and a chance for everyone to have their say. Some of the issues that came up at those early meetings have as much or more relevance today as they did then. We always emphasized the seriousness of having an animal protection agenda that was comprehensive and honest, along with the necessity of a truly fundamental and rigorous research agenda. In many cases, the first to identify these issues were not necessarily the board members but most likely to be representatives of each of these contingents. Leon Golberg, for example, made a critical point: If tissue culture methods were going to replace animal testing, we needed to develop assays using human cells in culture. This understanding was prophetic and absolutely correct. In fact, this became part of the initial research program of CAAT-funding research that would provide consistent human cell culture models. Human cells in culture and 3D models are now readily and commercially available. There is little question that this would have happened independently of CAAT, of course, but there is also little question that this approach in toxicology is one of CAAT's biggest successes.

\section{The U.S. Government and CAAT}

\section{$E P A$}

Jack Moore, an associate director of the EPA, agreed to serve on the CAAT Board. He understood and accepted our mission and wanted to help us get our message out. He invited me to make a presentation at the EPA facility in Washington, DC. The announcement of the lecture also identified that he would be introducing the speaker, guaranteeing a large audience. The room was full, with probably $200-300$ attendees. It was quite amazing. The EPA became the first of many groups to hear about CAAT and our mission. And it introduced me to speaking before large audiences.

\section{$F D A$}

Gerry Guest was our first FDA representative. He was appointed by the then director of the FDA. Gerry suggested that I arrange a program in DC for the FDA. As it turned out, it was the first of many over the years. I asked Gordon Sato, director of the Alton Jones Cell Science Center, to be the primary speaker and to discuss the state of the art in tissue culture. Gordon used two or possibly three slides, but mainly gave a chalk talk. He described how his science was focused on the components necessary to make cells grow in vitro. He was the first to use fetal calf serum to make a complete growing medium and showed how, compound by compound, he was eliminating the need for fetal calf serum by creating a defined medium. He showed how cells could be grown in vitro while maintaining functional responses.

At the end of the presentation, many in the audience came over to me and asked essentially, "Is he real? Will this ever be practical?" Much of this audience thought they had heard a science fiction talk, when in fact it was truly the beginning of advanced cell culture techniques. I date these events to 1982 .

\section{Letting Europe Know}

At this stage, there was limited research in Europe in toxicology and in vitro science. The Fund for the Replacement of Animals in Medical Experimentation (FRAME) had been formed in the 1960s and was mainly an animal protection organization. The Universities Federation of Animal Welfare (UFAW) was not very active. In Switzerland, The Swiss Center for Toxicology, headed by Gerhard Zbinden, was the true focus for mechanistic toxicology and in vitro sciences.

In 1982, on a trip to Europe, I made a point to visit with Gerhard. We did not know each other and we planned a one-hour meeting at his institute at $10 \mathrm{am}$. That meeting lasted until almost $4 \mathrm{pm}$. We discussed all aspects of the field and how we saw it developing. We became very close friends over the years and saw each other all over the world. Our wives also always looked forward to getting together. Many years later, when Mrs. Doerenkamp asked Gerhard to lead a foundation for realistic animal research (what was to become the Hildergaard Doerenkamp/Gerhard Zbinden Foundation, or DZF), he agreed. He called and told me I was joining the board and that I would be at every meeting, even if it was only one day long. I agreed. I think one of my major contributions was having the DZF establish endowed chairs to put the field on solid footing. The U.S.-based chair at Hopkins exists in perpetuity. Unfortunately, the chairs in Europe have been short-lived or will end when the current recipient is no longer at the respective university.

Alternatives soon became mainstream in Europe, with many countries establishing centers similar to CAAT. In addition, the European Union formed the European Centre for the Validation of Alternative Methods (ECVAM). Europe continues to have more centers devoted to the topic than anywhere else. In the United States, the EPA in 2004/5 requested that the National Academy of Sciences (NAS) do a study to 
help define the field. The report, Toxicity Testing in the 21st Century: A Vision and a Strategy, is a landmark document. More on that later.

\section{The Center and the University}

Within Johns Hopkins a new model was needed. We had essentially no knowledge of how to maintain our independence while working with a trade association that reported to many different companies, some with differing agendas. The Board of Trustees of the university is a policy-setting board. There cannot be two boards of trustees. An advisory board to CAAT was set up to advise the director and the school on issues related to CAAT. The corporate representatives were very wise and suggested that the academic members should make the decisions on the grants. All members could participate in the review process, but only the academics could vote. The process worked, and remains the same today.

CAAT, like all centers at the university, reports to a department and thus through the department to the dean's office. In my case, I was also an associate dean (for research, and later corporate affairs), and I had direct access to Dean D.A. Henderson. He was always, and still is, extremely supportive.

\section{The UK Center on Alternatives}

The House of Lords established a committee to look at creating an alternatives center in the United Kingdom. They visited CAAT, and I was invited back to meet with the committee. It was a great experience. My wife and I were invited to have lunch in the Peers Dining Room in the House of Lords. It was a wonderful experience, and at that lunch, I discovered how the dishes and silverware I had seen in museums could fit together like a puzzle.

The UK Centre on Alternatives was created as a direct copy of CAAT, including all of our documents and working protocols. It has evolved over time and is now a different but successful model.

In the 1990s, many other countries established centers devoted to the 3R's. Most, if not all, of these are currently active.

\section{The CAAT Programs}

Grants and the Avon program project

Information program and setting up the first website

Symposia programs evolving into the world congresses

Workshops and technical reports

Education programs

Refinement

Policy program

Board meetings

\section{The Grants Program}

CAAT's first initiative was the establishment of a Grants Program. Several people on the board recommended that we contact different academics and encourage them to submit grants. There was no guarantee that they would get funded, but they were encouraged to submit a one-page abstract on their proposed research. These abstracts were reviewed together and then several individuals were asked to submit full grants. The odds of getting funding were between $35 \%$ and $50 \%$. Writing a one-page abstract was not an onerous task for the great possibility of getting a grant. This model was well received and the Grants Program established the significance of the emerging field.

The grant review process was a combination of several different approaches. Once an abstract was selected, a grant application was requested, and the PI had 2 to 3 months to submit the grant. Detailed instructions were provided and are currently available on the CAAT website. Once the grant was submitted, it was then reviewed by three to four individuals with the appropriate expertise. These individuals were not on the CAAT board. They provided written reviews in a standardized format. The board then evaluated each grant and the written reviews. Three board members are typically assigned to review and score the grant at board meetings. The full board then discusses the grant, and the academic members vote. During CAAT's first 30 years, grant funding totaled \$6 million dollars-not a huge sum, but a most important stimulus to the field.

Jay Gandolfi, a former member of the board, once told us that the NIH study section (of which he was a member) considered it a positive endorsement if a researcher had been able to get funding from CAAT. CAAT grants were able to provide necessary preliminary data for the grant.

The logistics of organizing the grants and sending them out for the first review was, at the time, beyond the expertise of the secretarial staff ( 1 person), and I was not much use either. We were running out of time and packages that had to be mailed for board reviews were on the floor of the CAAT offices, incomplete and in partial disarray. Our secretary was in tears. The next day, my daughter Naomi came to the rescue. A teenager with phenomenal organizational ability and boundless energy, Naomi organized the entire process in a single day and all of the boxes (each weighing about nine pounds) of grants and reviews were delivered to each member of the board on time. Fortunately, electronic organization and transmission has since made this a very different and much more efficient process.

\section{The Avon program project}

Avon funded CAAT from the first CTFA grant and then continued independently funding the center. After a few years, Avon, in the person of Yale Gressel, asked if we could take on a larger project-developing an in vitro assay to predict skin sensitization.

We approached the problem by inviting about eight laboratories working on various aspects of skin biology to present to their "competitors and colleagues." They were asked how they would approach the issue, and what aspects they saw as most important. At first, the discomfort was obvious: "Will what I share be used by my competitors?" As the day progressed, however, it became clear that each lab would be focusing on different aspects of the problem. We invited five individuals to submit grant applications with the provision that, if approved, up to three applications would be funded. The funded projects would get together twice yearly in a roll-up-your-sleeves discussion about their progress and how to proceed. The attendees at these "lab" meetings were the participants, along with other experts from Hopkins, government, and Avon. And they were wonderful meetings. At 
almost every meeting a person from one of the sectors would ask a question and the response from another sector would be, "That is a great question-I would have never thought of it." In essence, the corporate and government scientists wanted to know how to use the information generated and the academics wanted to better understand the mechanisms involved.

The project lasted nine years, and the science it generated formed the basis of our understanding of mechanisms of skin sensitization. This project was summarized by Craig Elmets. ${ }^{5}$

By all measures it was a very successful project, characterized by identification of many of the interleukins, cytokine pathways, and the recognition that keratinocytes play an important role in sensitization.

\section{The information program}

It quickly became apparent that we needed to develop a communications program. Lots of people were interested in what we were doing, and so we put together a newsletter. With each new project we rarely got what we wanted at first, but as my son Michael says, "When you do not get what you want, you get experience." I got a lot of experience.

Over time we produced a very credible product that was informative, interesting, and well-respected. By the end of the 1990s, however, the cost of print and postage became prohibitive and we created our first website. A family member, Alex Menkes, developed our first website, our electronic newsletter, and helped define what the CAAT site would becomea portal to other sites as well as a provider of new information.

A few years later, Altweb was developed as a collective portal for many organizations. It quickly became the premier website for alternative news. The two sites continue today-the main CAAT site highlighting the center's programs and products, and Altweb as a portal for alternative websites worldwide.

Although not initiated by CAAT, two in vitro journals were established: Toxicology In Vitro in Europe and In Vitro Toxicology in the United States. The U.S. journal folded after a few years but Toxicology In Vitro is still active and very well-respected. Alternatives to Laboratory Animals (ATLA-a FRAME publication) is the longest running journal in the field. It focuses on animals, has a scientific and political agenda, and is recognized for its animal advocacy. ALTEX: Alternatives to Animal Experimentation published in Switzerland has grown over the last several years under the leadership of Thomas Hartung, and most recently Applied In Vitro Toxicology (AIVT) published its inaugural issue in March 2015. (Disclosure: I am a consulting editor and was an active participant in getting AIVT established.)

\section{First symposium}

In May 1982, we held our first symposium titled "Product Safety Evaluation." At the first break in this meeting, Frank Lowe asked me, "Did you see Spira's letter?" I said I had not, and he gave me a copy. It was addressed "Dear Alan" and had a large stamp "DRAFT" across it. It then went on to detail accusations fabricated to make me look as if I used the CAAT funds for personal gain. It didn't say that $d i$ rectly, but it was implied. The letter was brilliant, hand-typed with many cross-outs and corrections. Of course it was not sent to me but to members of the board and our sponsors, and I do not know who else.
I gave the letter to Cherrie Cleghorn, the Hopkins PR representative for the center. She read the letter and asked me, "Is anything in this true?" I told her none of it was. She asked again, "Are you certain?" and again I said yes. She took me by the hand and dragged me to find Henry. She then said to Henry (and I am paraphrasing), "As you know, none of this is true. If you can't prove it just shut up and help us get the work done we both want." This was a major turning point and was the beginning of a true friendship and collaboration between Henry and me. Henry and I always referred to the "draft" letter.

\section{From symposium series to world congresses}

The symposia series was held about every 18 months and focused on specific topics aimed at advancing the in vitro field. There were nine symposia and each resulted in a book in the In Vitro Toxicology series published by Mary Ann Liebert, Inc. (available on the CAAT website). (Alternative Methods in Toxicology, Vols. 1-11, Mary Ann Liebert Pub, New York.)

In 1990, I met and visited with Bert van Zutphen at the University of Utrecht at the suggestion of Joep van Bercken, my mentor on my first sabbatical in The Netherlands. I asked Bert if he would work with me on the first World Congress on Alternatives and Animal Use in the Life Sciences that would be held in Baltimore in 1993. Following working on the First World Congress, he would host the Second World Congress in Utrecht in 1996 and invite someone to join him from that congress to organize the Third World Congress. This established a pattern for subsequent world congresses. The Ninth World Congress was held in Prague in 2014, and the next is scheduled for Seattle in 2017.

Andrew Rowan, who organized the 2002 symposium, initiated a slightly more formal approach and created the Alternatives Congress Trust. This trust is now responsible for future congresses and guarantees their continuation.

The attendance at the first congress in Baltimore was slightly more than 600 . Prague had more than 1,000 attendees.

To fund the world congresses we had to go to the same sponsors that funded CAAT and were concerned that this could affect future CAAT funding. Unfortunately, we were correct. It took several years to recover CAAT's funds, while many multinational corporations, based in Europe, funded the world congresses rather than CAAT. Even with the short-term decrease in funding, however, we were able to maintain all programs and then grew again with foundation and private donor support.

At the World Congress in Japan (2007), CAAT celebrated its 25th anniversary. I was asked to present an article, which I titled "The Science of Alternatives: 25 Years and Tomorrow." The article $e^{6}$ presents a timeline of events related to the use of the rodent in biomedical research to the development of alternatives and in vitro approaches in toxicology. I did this by looking at each issue and its "initial truths" from 1981 and contrasted it with the "current realities" of 2008. The article featured many photographs of individuals involved at the time.

A series of detailed timelines devoted to the 3R's in toxicity testing was published by Martin Stephens and Nina Mak. ${ }^{7}$ Two websites associated with CAAT provide endless amounts of historical information. ${ }^{8,9}$ 


\section{Workshops and technical reports}

When John Frazier joined the CAAT team as associate director (1985-1994), we produced many workshops and most were published as technical reports. We wanted to share the information broadly and also wanted the workshops to be highly focused on limited topics. Many of these, if not all of them, are identified on the CAAT website.

In 1998, the Environmental Protection Agency (EPA), Chemical Manufactures Association (CMA), and Environmental Defense (ED) initiated the High Production Volume (HPV) Testing Program. To address the needs of this program, CAAT held several TestSmart workshops. The TestSmart workshops were well attended and supported. After the initial focus on HPV, we began a series of development neurotoxicity (DNT) workshops and the DNT series continues today.

One very important technical report was written by John Frazier while acting as a consultant to the OECD. ${ }^{10}$ This single-author report identified the science necessary for a validation study. It was the background piece that was rewritten as a multiauthored approach to validation. The validation literature rarely cites John's seminal article and this is an attempt to correct that.

\section{Education programs}

Joanne Zurlo, who was CAAT assistant director (19901993), associate director (1993-2000), and senior scientist (2010-), established an outreach and education program with CAAT's science writer Deborah Rudacille. Together they worked with artistic designers to create the CAATalyst newsletter for middle and high school students. The final issue of CAATalyst was a comic book, Adventures in TierTesting, in which Dr. In Vitro visited a cosmetic company to oversee the testing of a new acne cream. Another product of the outreach program was the book Animals and Alternatives in Testing-History, Science and Ethics, which was written to expose a nonscientific audience to the concept of the 3R's. ${ }^{11}$ The education program was coincident with the Baltimore City effort to stimulate science education.

\section{Refinement}

From the very beginning, the R of Refinement was very important to us. It had intermittent support from several sponsors and our refinement research was funded by a grant mechanism. We funded research at institutions worldwide that was initiated by animal technicians and postdoctoral fellows in comparative medicine groups for up to $\$ 6,000$ (for 1 year) to solve very specific animal welfare issues. The projects that were funded and were successful (almost all of them) were presented at the PRIM\&R annual meetings. They led to some remarkable advances. One example was using 3 " ring binders (stainless steel) attached to the tops of mouse cages as an exercise gym. The mice loved them and spent a lot of time doing gymnastics. The cage washers also liked them because they did not have to be removed to clean the tops of the cages. These grants have been money well-spent and funders, technicians, investigators, and countless animals all benefited. The program is currently active, led by Joanne Zurlo, and continues to be a success.

Currently, there are discussions ongoing at the Hopkins to expand the refinement program into a university-wide pro- gram dealing with animals, public health, and ethics. In fact, as I am writing this article, individuals from CAAT, The Berman Institute of Bioethics, and the Johns Hopkins School of Medicine are in discussions with the development office at the university. A symposium to initiate this activity is scheduled for December 2015.

\section{Policy program}

Paul Locke, an attorney and public health professional, joined the CAAT faculty in 2001, and initiated the Policy Program in 2007. This program is aimed at educating policy makers and legislators about the need for alternatives to the use of animals in toxicity and safety testing and in biomedical research.

Although a reasonably new program, it has achieved a life of its own, has grown rapidly, and is recognized as a separate program within the department of Environment Health Sciences.

Another important aspect of the program has been its outreach to the Animal Law Community. Strong ties have been established with the Lewis and Clark Center for Animal Legal Studies, the Animal Legal Defense Fund, and the Animal Law Section of the Maryland Bar. The program also maintains important strategic relationships with the National Academy of Sciences Institute for Laboratory Animal Research (ILAR) and the American Consortium on EU Studies (ACES).

\section{Board meetings: around the table}

Since CAAT's inception, there have been two board meetings a year. All board members are listed on the CAAT website. Over the 28 years covered in this history, there were 9 board members from Hopkins. These included D.A. Henderson, Gareth Green, Henry Wagner, Frank Loew, Jim Yager, Cecile Pickart, Noel Rose, Sol Snyder, and me. At the fall meetings we reviewed grants and CAAT programs, and the spring meetings were used to attract new sponsors and update the board on alternatives-related activities. In the years we held board retreats, the retreats replaced the spring meetings.

It is quite common for meetings to start with each person introducing him- or herself to the group. We did this, but in addition, each board meeting and each retreat always ended by individuals going around the table again. This was to make sure that everyone had a chance to restate a point, and, most importantly, share what they were doing in the world of alternatives. We always left at least an hour to go around the table. At workshops and other small attendance projects, I also always ended this way. At a recent DNT workshop, as I closed the meeting, I went around the room. One shy scientist, who spoke English hesitantly and had not said a word the entire meeting, presented his thoughts about future needs. It was an important contribution. About a week after the meeting, I received an e-mail from him, thanking me for giving him the opportunity to make his point.

The around-the-table concept is a defining characteristic of CAAT meetings.

\section{Working with Sponsors and Donors: Lessons Learned}

The following is a small selection of events that occurred during the first 20 or so years of CAAT. 


\section{Having someone look over your} shoulder-The First Progress Report

Until we received the CTFA grant, I was funded by NIH and other federal sources. The government grants required yearly progress reports, and I am rather convinced that no one ever read any of my progress reports.

At CAAT, we also asked for yearly progress reports. These were specific requests for feedback on how the previous year's goals were met and what the work product for the coming year would be and were reviewed by the CAAT board. Funding was dependent upon whether the goals of the previous year were met. Occasionally, the reasons for not meeting the selfestablished goals and the anticipated work product convinced the board to continue funding. However, we had an overall "do-not-re-fund" rate of approximately 20\%-which was okay with us, as our research pushed the envelope and, as such, we did not expect all of our projects to come to fruition.

The CTFA grant required quarterly progress reports. In the first progress report, I detailed concepts we had developed, how we were going to reach out to the scientific community to get grants, who we had spoken to, as well as providing the status of the board (which was not yet fully established, with the first meeting still three or four months away). The day the report reached CTFA I got a call from Norman Estrin, the CTFA scientist who was the representative to the CAAT board. When I got the message Norman had called, I thought (possibly out loud), "They got the first report and already they are complaining." I returned the call and Norman answered. He said, "Your report is a great summary of progress. We hired the right group." I realized that up until then I had been brainwashed to think of industry sponsors as the "bad guys." How wrong I was. In fact, the CTFA was extraordinarily helpful throughout their many years of support.

\section{Learning to love hamburgers}

A few weeks after CAAT was established I was invited to lunch with several different people from the cosmetics industry. In fact, two lunches were scheduled a day apart, both in Manhattan. I was trying to meet all the players to understand who I was working with (and to gauge their expectations).

We all looked at the menus. There seemed to be a hesitation as the orders were placed. I ordered a salad with salmon. The lunch was fine and the meeting productive. I even got an invitation or two to visit with specific companies. A while after the lunch, I realized what had happened. The others at the table did not know-because of the animal welfare issue-if I was a vegan, vegetarian, or omnivore (which I am). Would they insult me if they ordered meat? I realized they had all ordered nonmeat lunches.

The next day, while having lunch with a similar but different group, I had a plan. At that time, hamburgers were not really part of my diet. When the waitress approached, I ordered a hamburger. The others ordered easily and there was none of the awkwardness of the previous day. Problem solved. Yes, today, I do eat hamburgers (generally from grass-fed and pastured animals) but that is a different story, and related to my work on food issues.

\section{Lesson from a donor}

The development office at the school received a letter offering CAAT a house and its associated property worth approximately $\$ 1$ million. The idea was to establish a charitable remainder trust, in which the donors would receive a quarterly U.S. government rate of return through their lifetime and then the trust would belong to CAAT. This was the first such gift that the center received. I didn't know the people and no one at the university had any contact with them prior to their offer. Before I would let the university accept the gift, I wanted to make sure that these donors understood who and what we were, and so I paid them a visit. I met them in the yard of their home, which was close to the property being given to the university. It was a lovely spring day, and we were served lunch under a large tree while we watched many animals in the fields.

I indicated that I was very pleased with their generosity and wanted to make sure they understood what we did and how we did it. It was clear they understood our work and our mission, and so I gladly accepted the gift. The land was sold by the university and the resulting trust is active and has paid its quarterly payments for many years-and hopefully many, many more to come.

\section{A learning moment}

Early in CAAT's history I was invited to give a presentation to the annual meeting of an international animal protection group. There were several hundred people in attendance. Tom Regan, a philosopher at North Carolina State University, preceded me and gave a very powerful presentation in the style of a minister. He pointed out that books on women's rights also contained chapters on animal rights and he pounded the podium. His points were clear, powerful, and delivered with fanfare. He may have gotten a standing ovation. I was the next speaker. My message was that alternatives will eventually replace animal testing, but it will take time-a long time. Science, I told the crowd, does not work quickly. The Q\&A session for my presentation ran way over its allotted time. The questioners were interested but highly critical and believed that no animals should be used in product testing.

I went to the banquet that evening. When Henry Spira saw me, he told me that I was brave to even think about attending the banquet. When I entered the room I was suddenly isolated by a circle of people who all turned to face away from me. I was in a sea of backs. Eventually, a few people broke through the circle and posed more questions for me.

One woman in her 60s asked about heart valve replacements and how were they tested. I explained that the valve was probably from a pig, and that the technique was mainly developed and tested in dogs. "I was afraid you would say something like that," she replied. "My husband had a valve replacement. He is doing well and I love him, but if I knew that the valves were tested in dogs, I would not have allowed him to have the surgery."

The lesson was clear. She is not atypical. Most people in the animal protection community are honestly committed to animal welfare and to the protection of animals.

\section{An ASPCA awards luncheon}

Each year, the ASPCA holds an awards luncheon to honor truly special individuals and animals. Gigi Kwik (now Gronvall), a CAAT grantee and student in the department of biology, was being honored and I joined her for the event. I was 
seated next to a woman who had a business in NYC and who was also a substantial donor to PETA. During the conversation she asked about the effectiveness of PETA's approach to reducing animal use in research. I shared what I knew-I have never been impressed with PETA's so-called accomplishments, and the personal attacks on individual scientists only made many of them dig in their heels rather than think about alternatives. I explained that there may be a long-term approach to achieving her goals and described how CAAT worked and our approach would eventually achieve the desired reduction (and elimination) of animals from cosmetic testing.

After numerous meetings and discussions, she said "CAAT's approach makes sense, but the activism appeals to me," and she continued to contribute to PETA.

\section{"Can't you do better?"}

One of the finest pleasures I had as director of CAAT was continually meeting many influential people from all walks of life. I'm not sure how we actually met, but my wife and I had the opportunity to have dinner with Margot Adler (of National Public Radio) and her husband. One of my expectations of the dinner was to better understand why the press seemed to be less than supportive of CAAT. It was a wonderful dinner in a small Spanish restaurant on the Upper West Side of NYC. Our discussion was easy and far-ranging, and I left with a better understanding of how the press functions. When I asked why the press coverage of alternatives was less than positive, Margo answered, "I know you're doing all that you can, but can't you do better?' We were a work in progress-doing well, but nowhere near the goal of ending animal testing for cosmetics.

As I write this, for all practical purposes we have gotten out of animal testing for cosmetics. I say "for all practical purposes" to qualify that some countries (Brazil and China, for example) still require animal testing. And some companies, for some areas, do limited testing to be certain of toxicity results or simply as legal insurance. But we are very close to the end of animal testing for cosmetics. We have, in fact, done better.

\section{CAAT retreats: strategic planning}

CAAT was funded in 1984 with a second three-year grant from the CTFA. We were also told that the CTFA grant would thereafter decrease, but that we could now fundraise directly from their membership. Around the beginning of our fourth year, we planned our first retreat to examine where, what, and with whom we should be working with in the future.

Retreats were held in Scottsdale, Arizona; Isle of Palms, South Carolina; Laurentian Mountains, Canada; Woods Hole (NAS), Massachusetts; Lake Louise, Canada; Santa Rosa, California; Tucson, Arizona; and Tarrytown, New York.

Each retreat explored specific functions. I will share the details of two retreats that truly exemplify their purpose and function. As a side note, all other CAAT meetings took place in Baltimore (with a few in DC to attract government scientists).

The planning, the involvement of the board, and a common shared agenda of all the retreats were aimed at one goal: to do good for CAAT.

At the Lake Louise Retreat (2000), I told the board it was time for me to step down. I was gently told I could consider that in "three years or so." When I discussed this with the dean of the school, Dean Sommer, he asked that CAAT do a self-study similar to what a department would do every five years. As far as I know, this was the first for any center at the school. It turned out to be a great experience, and it took almost a year to pull all the material together and evaluate every aspect of our activities. Once completed, we held the California retreat (2003). At this retreat the board dissected and evaluated every aspect of our activities and wrote the conclusion (what had been accomplished) for each program. It was an incredibly comprehensive, strongly worded, and very positive review, and was submitted to the school. The university then set up an internal review committee. The internal review, which took more than a year, was also very positive and the search for a new director was launched.

\section{The Tucson retreat: toxicology testing in the 21st century}

I share this retreat as an example of what I consider a real strength of CAAT and one of its major contributions to our supporters.

The NAS report, Toxicity Testing in the 21st Century: A Vision and a Strategy, was in its final stages of publication. It had undergone external review and I was one of the external reviewers.

When the NAS established the board for the study, I was not consulted as to its membership, and, in fact, there were several names I did not recognize. What struck me, however, was that more than $50 \%$ of the membership was either current or past CAAT grantees or board members. To this day, I do not know how the membership was selected, but the NAS chose well.

The final report was in press and I received permission for the CAAT board to have access to the document. The report was released to the public shortly after the retreat.

At the retreat, every board member was assigned sections of the report to review, with several board members reviewing each section. Board members then made presentations on how the report would affect them as academic scientists, regulators, and corporate scientists. The importance of this study and the potential impact on the future of toxicological risk assessment were made known to our board ahead of the study's public release.

The major conclusions of the study included the following:

1. Animal studies are time-consuming and expensive.

2. There is a lack of predictability of animal studies as they relate to humans.

3. We should be using human cells in culture.

4. We should explore systems biology and pathways and mechanisms of toxicity.

As a personal aside, this publication was, and is, a major advancement in in vitro toxicology, alternatives, and risk assessment. It created major new research approaches and opportunities. Only the future will tell us how far it will take us, of course, but its conclusions demonstrate how far CAAT advanced the field.

\section{CAAT's 20th anniversary: September 11, 2001 (9/11)}

About 140 people from around the globe attended CAAT's 20th Anniversary Symposium. I believe it was in 
the middle of the presentation of our first speaker, Pamela Contag (then co-CEO of Xenogen), when Bernard Schwetz, acting director of the FDA, called me to the door. He was as white as a ghost. I immediately knew something was very wrong. "Alan," he said, "I can't do my presentation. I have to leave-there's been a terrorist attack on the U.S.', I looked around the lobby of the hotel and all seemed very normal. I went back into the room and took my seat. There was nothing I could share at that point. A few minutes later Marilyn Principe, a senior CAAT staff member, came in and gave me the first details of 9/11. I walked on the stage, interrupted Pam, and let the audience know what was happening. We all went into the lobby to watch the scenario unfolding on TV. Several people left in an attempt to get home, but most stayed, and after 30 minutes the group decided to not let the terrorists destroy everything. They voted with their feet to continue where we left off. Pam completed her presentation and all the others gave theirs.

Air travel was totally stopped. Few people could leave and so we arranged hotels, group dinners, and office space for about a week while our attendees were stranded. A group of colleagues showed up at my home every evening after dinner. When everyone was finally able to get out of Baltimore, our late evenings seemed empty — and the world had changed.

\section{Friendships}

Friendships are very important to me. Although I knew a few of the board members before they came aboard, most were assigned by their respective government agency or corporation, and prior to their appointment to the board were strangers. Some of the academics were recommended by other board members but again, I did not know them. Over the 28 years, however, many of the board members and their partners became friends with me and my wife. We have dined together around the world, participated in each other's life events, and have stayed at each other's homes. We have become true friends. We have done good work together, but to me these friendships are an unequalled aspect of my experiences with CAAT.

\section{Accomplishments}

(This section was compiled after asking several current board members/CAAT staff for their feedback on our accomplishments; what follows was identified by them.)

- CAAT, as part of Johns Hopkins University, gave the 3R's legitimacy and credibility by guiding its activities through good science.

- CAAT provided the funding for the development of in vitro assays (science) that are actually in use today, and are accomplishing the goal of the 3R's.

- CAAT trained students in the 3R's, supported career development, and helped shape the concept of alternatives through its support of original research.

- CAAT, through many mechanisms-including meetings, workshops, small planning meetings, development of the world congress, and publications-brought people together.

- CAAT clearly defined its mission and presented its mission to regulatory agencies, academia, science, and the general public.
- CAAT serves as an honest broker and provides "neutral territory" in a contentious area (and not all activist communities saw us in this light).

- CAAT served as a source of credible information about the relevant science, policy issues, and ongoing developments in in vitro sciences and alternatives.

- CAAT provided seed money for important research through its grants program, program projects, and refinement research.

- CAAT played an important role in developing validation principles.

- CAAT developed the concept of the World Congress on Alternatives and hosted the first World Congress in Baltimore in 1993.

These are only the highlights of CAAT's many accomplishments. They are the results of the effort of a great many people. Some have been identified in the text; others are included in the acknowledgments.

\section{New leadership, the future}

In 2009, Thomas Hartung was appointed director of CAAT. Thomas and I first met in 1996 at the World Congress in The Netherlands, where he shared the Gerhard Zbinden/Hildergard Doerenkamp Award with Albrecht Wendel.

Thomas and I interacted again when he was appointed to head ECVAM in 2002. From that point we had shared numerous activities. I was extremely pleased when Thomas accepted the university's offer to be the second director of CAAT and we started to work together. When he accepted the position, he asked me to chair the board, and be a principal in the Transatlantic Think Tank for Toxicology $\left(\mathrm{t}^{4}\right)$ collaboration. I was reluctant as Dean Klag requested (as was appropriate) that I essentially - in a nice way, of course"disappear." It was time to let the new director take over. I had already started working on farm animal welfare issues and responsible (ethical) eating, and was willing to fully engage in this activity. Before I accepted the ongoing relationship with CAAT, I told Thomas that he had to clear it with the dean, but if Mike approved, that I would accept. On November 19th, 2014, I chaired my last grant review at the board meeting and turned the chair (interim) over to James Freeman (ExxonMobil).

Thomas's influence on CAAT is significant. He initiated the $\mathrm{t}^{4}$ program, the Evidence-Based Toxicology Collaboration (EBT), a metabolomics laboratory at Hopkins, and CAAT-Europe. Each of these is described on the CAAT website. All of the other programs have continued-some as they were and others with modifications.

It has been a remarkable 28/33-year experience. Writing this history has been great fun and hopefully codified how and why we did what we did.

\section{Acknowledgments}

There are so many people who made CAAT special. First and foremost are the Hopkins colleagues who were with me in the beginning and are identified in the text. The Advisory Board members as individuals and as a group were truly selfless and always thought about what was best for the center. Their advice and friendship made CAAT what it is. During 
parts of the first 28 years, there were two CAAT faculty members who provided invaluable assistance and direction: John Frazier and Joanne Zurlo. I am deeply appreciative of their contributions. Many of the staff were with me for years and years-Marilyn Principe, Joan Poling, Jeannene Tylee, Ruth Brady, Lisa Leibowitz, Carol Howard, Ben Choi, Michael Hughes, Liza Mohamed, and Deborah Rudacille. They made the office a place I always enjoyed going to. In addition to the CTFA and many corporate sponsors, we were funded by an anonymous donor, with great generosity. I am most thankful.

An early draft was reviewed and fact checked by D.A. Henderson, Marilyn Principe, and Helene Goldberg. Joanne Zurlo and James McKim reviewed the penultimate draft. Final editing and locating archival pictures was graciously done by Michael Hughes. I thank each and every one of you.

There are two very special people who were both cheerleaders and critics, but always incredibly supportive. Henry Spira, after the "draft letter," became a close friend, collaborator, and important part of my life. Most importantly is my wife, Helene; she is my best friend, the most important person in my life, and she is a woman of valor. Helene, I could not have done it without you. I am truly lucky.

\section{References}

1. Brooks N, Goldberg AM. Choline acetyltransferase activity of spinal cord cell cultures is increased by diisopropylphosphorofluoridate. Life Sci 1979:24;889-894.

2. Goldberg AM. Mechanisms of neurotoxicity as studied in tissue culture systems. International Workshop on the Application of Tissue Culture in Toxicology, The Netherlands. Toxicology 1980:17;201-208.
3. Goldberg AM, Brookes N, Burt DR. The use of spinal cord cell cultures in the study of neurotoxicological agents. Toxicology 1980:17;233-235.

4. Kuhn T. The Structure of Scientific Revolutions. Chicago: Chicago University Press; 1970.

5. Elmets C. The AVON Program Project. A report of progress. In Vitro Toxicol. 1996:9;223.

6. AATEX. Proceedings of the 6th World Congress, 2007, Tokyo, Japan. Special Issue, pp. 29-36. altweb.jhsph.edu/ wc6/paper29.pdf (last accessed May 26, 2015).

7. Stephens M, Mak N. The 3R's in Toxicity Testing - From Russell and Birch to 21st Century Toxicology. In: Reducing, Refining and Replacing the Use of Animals in Toxicity Testing, Issues in Toxicology. Allen D, Waters M. (eds); UK: Royal Society of Chemistry; 2014.

8. Johns Hopkins Bloomberg School of Public Health. ALTWEB. http://altweb.jhsph.edu/ (last accessed May 26, 2015).

9. Johns Hopkins Bloomberg School of Public Health. CAAT. http://caat.jhsph.edu (last accessed May 26, 2015).

10. Frazier J. Scientific criteria for validation of in vitro toxicity tests. OECD Environmental Monographs \#36, 1990.

11. Zurlo J, Rudacille D, Goldberg AM. Animals and Alternatives in Testing-History, Science and Ethics. New York: Mary Ann Liebert, Inc; 1994.

Address correspondence to: Alan M. Goldberg Bloomberg School of Public Health Johns Hopkins University 615 N. Wolfe Street, Room E7032 Baltimore, MD 21205

E-mail: agoldbe1@jhu.edu 